Originally published as:

Conrad, A., Seiwert, M., Hünken, A., Quarcoo, D., Schlaud, M., Groneberg, D.

The German Environmental Survey for Children (GerES IV): Reference values and distributions for time-location patterns of German children

(2013) International Journal of Hygiene and Environmental Health, 216 (1), pp. 25-34.

DOI: 10.1016/j.ijheh.2012.02.004

This is an author manuscript.

The definitive version is available at: http://www.sciencedirect.com/ 


\section{The German Environmental Survey for Children (GerES IV): Reference Values and Distributions for Time-Location Patterns of German Children}

\section{Authors}

André Conrad $^{1,2}$, Margarete Seiwert ${ }^{2}$, Andreas Hünken ${ }^{2}$, David Quarcoo ${ }^{1}$, Martin Schlaud ${ }^{3}$, David Groneberg ${ }^{1,4}$

\section{Affiliations}

1) Charité - University Medicine Berlin, Institute of Occupational Medicine, Germany

2) Federal Environment Agency, Department for Environmental Hygiene, Berlin, Germany

3) Robert Koch Institute, Department of Epidemiology and Health Reporting, Berlin, Germany

4) Goethe University, Institute of Occupational, Social and Environmental Medicine, Frankfurt am Main, Germany

Author responsible for correspondence

André Conrad

Federal Environment Agency (Umweltbundesamt)

Department for Environmental Hygiene

Corrensplatz 1, 14195 Berlin, Germany

Phone: $\quad+49308903-1715$

Fax: $\quad+493402104-1715$

E-mail:

andre.conrad@uba.de

Word count (excluding abstract, figures, tables, and references) 


\section{Abstract}

Children's time-location patterns are important determinants of environmental exposure and other healthrelevant factors. Building on data of the German Environmental Survey for Children (GerES IV), our study aimed at deriving reference values and distributions for time-location patterns of 3-14-years-old German children. We also investigated if GerES IV data are appropriate for evaluating associations with children's health determinants by linking them to data of the National Health Interview and Examination Survey for Children and Adolescents (KiGGS).

Parents reported on the time their children usually spend at home, in other indoor environments, and outdoors. This information was characterized by statistical parameters, which were also calculated for different strata concerning socio-demography and the residential environment. Consequently, group differences were evaluated by t-tests and univariate ANOVA. Reference distributions were fitted to the time-location data by a Maximum Likelihood approach to make them also useable in probabilistic exposure modeling. Finally, associations between data on the children's physical activity as well as body weight and their outdoor time were investigated by bivariate correlation analysis and cross tabulation.

On daily average, German children spend $15 \mathrm{~h}$ and $31 \mathrm{~min}$ at home, $4 \mathrm{~h}$ and $46 \mathrm{~min}$ in other indoor environments, and $3 \mathrm{~h}$ and 43 min outdoors. Time spent at home and outdoors decreases with age while time spent in other indoor environments increases. Differences in time-location patterns were also observed for the socio-economic status (SES) and immigration status. E. g., children with a high SES spend 24 min less outdoors than low SES children. Immigrants spend on daily average 20 min more at home and 15 min less outdoors than non-immigrant children. Outdoor time was associated with parameters of the residential environment like the building development. Children living in 1- or 2-family houses spend more time outdoors than children living in building blocks ( 3 h 48 min vs. 3 h 29 min). Physical activity correlates with outdoor time. For children with diminished age-specific outdoor time, a higher prevalence of obesity was observed (odds ratio: 3.2, 95 \% Cl: 1.5 - 7.1).

GerES IV provides a compilation of current time-location reference values and distributions on German children. This data hint to substantial differences in time-location patterns within the population to be considered in environmental health risk assessment. 


\section{Introduction}

Children's health is well known to be particularly vulnerable to various environmental stressors, such as noxious chemicals in food, air pollutants, UV radiation, and noise (Tamburlini et al. 2002; Landrigan et al. 2004). The health relevance of these environmental stressors is generally associated with the dose of exposure, e. g. the inhaled amount of particulate matter or the experienced noise level. As the presence of environmental stressors varies substantially between different environments (Frumkin 2005), children's time-location patterns are important determinants of their health-relevant exposures: The time usually spent indoors, as well as outdoors, influences, i. a., the exposure to various airborne contaminants (Hubal et al. 2000). Children's time-location patterns are, moreover, associated with other determining factors of health: Time children spend outdoors is known to be positively correlated with their physical activity (Sallis et al. 2000). Veitch et al. (2006) proposed time children spend outdoors as a proxy for physical activity. Recent studies by McBrien et al. (2008) suggest that outdoor time may protect children from developing myopia. It also has been hypothesized that lack of vitamin D in children may partly be due to insufficient outdoor time, but no profound epidemiological evidence has been presented so far (Ali et al. 2009; ElizondoMontemayor et al. 2010).

Several studies conclude that children's time-location patterns have changed in the last decades. The literature on this issue however in not entirely consistent: Several authors reported an increase of indoor activities such as watching television and playing computer games and decreasing outdoor activities like walking or biking to school or organized sports (Dollman et al. 2005; Ham et al. 2008; Hofferth 2009). In contrast, other studies observed an increase in children's organized activities while sedentary activities like watching television have decreased (Sturm 2005).

Against this background, sound and up-to-date information on children's time-location patterns is essential for risk assessment and management aiming at improving health outcomes. As opposed to other countries (e. g. Leech et al. 2002) recent data on German children's time-location patterns are scarce. Therefore, data on the time German children usually spend in different locations have been obtained within the framework of the German Environmental Survey for Children (GerES IV). 
Building on these data the main objective of our study was to generate comprehensive statistical reference values on the time-location patterns for Germany's children population. Children's time-location patterns are potentially influenced by age, gender, season and daytype, socio-economic and immigration status, and parameters of the residential environment. To give initial indications of current differences within the population and enable differentiated risk assessment, the reference values were stratified by these factors. For risk assessment problems of high complexity the interindividual variability in timelocation patterns might often be required at a level of detail that is beyond a set of reference values. As these problems are usually solved by means of probabilistic exposure modeling, the study also aimed at fitting reference distribution functions to the GerES IV data that reflect the variation within the population to a maximum degree.

Taking physical activity and overweight as examples, we also investigated whether GerES IV data are appropriate for evaluating associations between children's health determinants and their time-location patterns. For this, we linked GerES IV data to data of the National Health Interview and Examination Survey for Children and Adolescents (KiGGS) on an individual basis.

\section{Methods}

\subsection{Survey design}

The German Environmental Survey (GerES) is a representative cross-sectional study on the German children and adult population. The main goals of GerES are to analyze and document the extent, distribution and determinants of exposure to environmental pollutants. Hitherto GerES has been carried out four times since the mid-1980s, including up to 5,000 participants per survey. GerES IV was performed from 2003 to 2006 and focused exclusively on children. A total of 1,790 children aged 3-14 years from 150 German sampling locations participated in this survey. GerES IV is a module of KiGGS, conducted by the Robert Koch Institute, and the GerES IV data were obtained on a random sub-sample of all KiGGS participants. Thus, environmental data could be linked to health-related data on an individual basis. Because of this close co-operation, a profound set of health data is available for all GerES IV participants (Kurth et al. 2008; Schulz et al. 2007). 


\subsection{Questionnaire data}

In GerES IV standardized face-to-face interviews were performed with older children and all parents. Interviews as well as data and quality management were carried out by the Robert Koch Institute (Dölle et al. 2007).

Specific composite indices, representing the socio-economic status (SES) and the immigration status of children participating in KiGGS and GerES IV, were derived from data of self-administered questionnaires, to be used as essential stratifying variables in statistical evaluation (Lange et al. 2007; Schenk et al. 2007).

\subsubsection{Time-location data}

As part of the interview, parents of all GerES IV participants were asked about the average time in minutes their children spend at home, differentiating between weekdays and weekend. Both amounts of time were separately obtained for winter and summer. The same set of questions was asked for the time usually being spent outdoors. The remaining time completing the 1,440 min per day was defined as being spent in other indoor environments, e. g. at school or relative's residences. Obtaining these data was based on a parental recall of the child's activities within the last typical week. The interviewers were instructed to individually support this recall by asking for the child's common activities and corresponding locations. The interviewers also cross-checked the reported durations with other interview items such as the time the child usually spends in his or her room. Moreover, they assisted in summing-up the different amounts of time and converting them to minutes per day. Regular stays in other residences, e. g. in children of divorced parents or families owning weekend homes, were also considered for validating time-location data recording.

\subsubsection{Data on the residential environment}

A basic classification of the residential environment the GerES IV participants lived in was derived from the sampling location's community size. The GKBIK10 scheme was used for categorizing the community size according to the number of inhabitants and extent of commuting into ten groups (Aschpurwis + Behrens GmbH 2001; Behrens 2005). In order to better detect differences due to community size, the GKBIK10 classes were unevenly combined to three strata: GKBIK10 classes 1 and 2 were defined as the first stratum (less than 5,000 inhabitants), GKBIK classes 3 to 8 were defined as the second stratum (at least 
5,000 - less than 500,000 inhabitants), and GKBIK10 classes 9 and 10 were defined as the third stratum (at least 500,000 inhabitants).

For collecting more specific information at the neighborhood level, the GerES IV interviewers characterized the residential environment of each child's home on-site. The interviewers categorized, i. a., the type of the residential area (degree of urbanization) and the surrounding building development. For evaluating the interviewer ratings of the type of building development, one- and two-family houses were combined into one stratum, as they represent comparable building types. The resulting three-level variable yields a sufficient sample size for statistical analyses in each level.

\subsubsection{Data on the children's physical activity}

In the KiGGS study, children of at least 11 years of age were asked about their physical activity behavior and the average hours of leisure time per week they are involved in strenuous physical activity. In contrast, regular physical activity of children up to 10 years of age was only evaluated by parental report. In order to have a uniform variable on physical activity across all age groups, the parental assessment of their children's usual outdoor activity (up to 10 years of age) and study participants' self-assessment of usual sports and other physical activity (11-17 years) were combined into one uniform, ordinal scaled variable, rating the overall physical activity of all KiGGS and GerES IV participants indicating the frequency of physical activity per week (Lampert et al. 2007).

\subsection{Physical examination data}

Within the KiGGS study, children's body height was measured as described by Kleiser et al. (2009). The body mass index (BMI) was calculated and then categorized according to standardized definitions for overweight and obesity of the International Obesity Task Force (Cole et al. 2000) as well as the cut-off values derived for German children and adolescents by Kromeyer-Hauschild et al. (2001). The latter study defined overweight and obesity by the age- and gender-specific $90^{\text {th }}$ and $97^{\text {th }}$ percentiles of the BMI, respectively. This definition has been recommended to be applied for German children by Kurth and Schaffrath Rosario (2010).

\subsection{Data acquisition and statistical analysis}

Questionnaire data on the time the children usually spend at home and outdoors underwent detailed plausibility checks. The interviewers were advised to ask for the time again if the 
answer did not fall within an age-specific range of plausible values. This range especially considered the child's requirement to attend school. After data collection implausible and impossible values were deleted from the data set. Cases with incomplete reports on the time spent in different locations were likewise excluded from data analysis. Comparative calculations considering also cases with incomplete time-location data revealed only negligible differences to the final results solely based on cases with complete information on time-location patterns.

In addition to basic socio-demographic variables the choice of variables used as parameters for stratifying the time-location data was based on an initial explorative screening of the various KiGGS and GerES IV variables. The final stratification was carried out considering also the applicability of the reference values for general exposure modeling purposes. Statistical analyses were carried out using SPSS for Windows 17 (SPSS Inc. 2008) applying GerES IV-specific case weights (Kamtsiuris et al. 2007) for achieving representativeness for the German population. The add-on module SPSS Complex Samples was used for calculating standard errors and confidence intervals, as the survey sampling involved the selection of clusters (the 150 sampling locations) in a multistage procedure (Schulz et al. 2008). As the different durations were close to symmetrically distributed and no critical deviations from normality were be observed, the arithmetic mean was used as measure of location. For evaluating differences in mean durations between sub-groups, two-tailed Student's t tests or one-way analyses of variance (ANOVA) were applied.

\subsection{Fitting statistical distributions to time-location data}

Fitting statistical distributions reflecting the different time-location datasets was carried out in a stepwise approach (Mosbach-Schulz et al. 2006):

1) The dataset was initially divided by gender allowing separate evaluation of the timelocation data. Regarding age a fine initial stratification scheme of one-year-strata was used. These strata were then combined to larger homogeneous age groups. The best split in different age groups was determined by comparing $F$ statistics relating interand intra-strata variability.

2) For each age group a Generalized $F$ (GF) distribution was fitted to the data by Maximum Likelihood estimation applying GerES IV case weights. The fitting algorithm 
also considered a possible point mass at zero (PMZ), reflecting the fraction of individuals spending zero minutes in a certain location ${ }^{1}$.

3) The four-parametric GF distribution provides high flexibility for parametric modeling (Peng et al. 1998), though being not supported by most modeling tools. The fitted GF distribution was therefore transformed to five common distributional sub-models with fewer parameters: The Log-Logistic, Log-Normal, Gamma, Exponential, and Weibull distribution are specific forms of the GF distribution (Ciampi et al. 1986) and are normally used for modeling durations (Hensher \& Button 2000).

4) These five derived sub-models were ranked by their goodness-of-fit according to the Likelihood ratio of GF and sub-model. The goodness-of-fit of the different distributions was confirmed by visually examining probability plots $(Q-Q$ and $P-P$ plots). Additionally, Kolmogorov-Smirnov (KS) test statistics were calculated, reflecting the largest distance between GF model and empirical data or, respectively, between the GF and the distributional sub-model.

All four steps of this approach were implemented using SAS 9.2 (SAS Institute Inc. 2010). All fitted density functions and corresponding percentiles for the GerES IV time-location data in the different gender/age groups have been transferred into the database for German exposure factors RefXP. The SAS script for distribution fitting and the RefXP database have been developed within the Xprob project on probabilistic exposure assessment (Mekel et al. 2007) and are freely available on the internet at www.uba.de/xprob .

\section{Results}

\subsection{Reference values for German children's time-location patterns}

This section provides statistical parameters describing German children's time-location patterns. These reference values were also calculated for several sub-groups to identify factors associated with the time German children usually spend in different locations.

\subsubsection{Differences by age and gender}

Tab. 1 summarizes the time German children spend at home, in other indoor environments, and outdoors stratified by age group and gender.

\footnotetext{
${ }^{1}$ Considering PMZ in exposure modeling is discussed for example by US EPA (2000).
} 
The average time German children spend at home each day is $15 \mathrm{~h}$ and $31 \mathrm{~min}$. The interquartile range is almost $2 \mathrm{~h}$ per day (14:34 - 16:30). The daily time spent at home reveals several group differences (see Tab. 2). 

models. Tab. 4 provides each GF fit and each best fitting two-parametric distribution 
omitting stratification by age and gender. Distributions for the different age/gender subgroups are available in the RefXP database.

[Tab. 4 about here]

GF and sub-models exhibit a good fit to the data. Corresponding KS statistics result in values close to zero. Only for the time spent in other indoor environments a fraction of zero minute reports had to be considered as PMZ. With less than $0.5 \%$ of children spending no time in other indoor environments on a typical day, this fraction is quite small.

\subsection{Associations between outdoor time and physical activity as well as body weight}

Combining KiGGS and GerES IV data sheds light on how outdoor time is linked to physical activity in German children. Moreover, BMI data obtained in KiGGS are appropriate for evaluating associations between overweight as well as obesity in children and their outdoor time.

The outdoor time is positively associated with the overall physical activity status derived within KiGGS: Children with a low physical activity status spend on average $3 \mathrm{~h}$ and $32 \mathrm{~min}$ outdoors (95\% Cl: 3:24 - 3:40). For children with a medium and high physical activity status the mean outdoor time was $3 \mathrm{~h}$ and $43 \min (3: 36-3: 49)$ and $3 \mathrm{~h}$ and $53 \min (3: 45-4: 01)$, respectively. This association proved to be highly significant $(p<0.001)$ also when considering age as covariate in the analysis of variance.

The hours per week the 11- to 14-year-old children reported to be physically active in KiGGS significantly correlate $(p<0.001)$ with parental reports on the outdoor time in GerES IV. The partial correlation coefficient controlling for age resulted in 0.18 (Pearson's product-moment correlation) and 0.22 (Spearman's rank correlation), respectively.

Fig. 2 displays the odds ratios of little outdoor time and overweight as well as obesity using the Kromeyer-Hauschild definitions for categorizing the children's bodyweight. Little outdoor time is defined by the age group-specific $5^{\text {th }}$ and $10^{\text {th }}$ percentile, respectively.

[Fig. 2 about here] 
Obesity is associated with outdoor times lower than the age group-specific $5^{\text {th }}$ percentile. The odds ratio resulted in 3.2 (95\% Cl: 1.5 - 7.1). No significant association is observed for overweight with a substantially lower odds ratio of 1.8 (95 \% Cl: $0.9-3.5)$. The same calculations were additionally carried out for summer and winter outdoor times, confirming the results for the overall outdoor time.

Defining the age group-specific $10^{\text {th }}$ percentile as cut-off for little outdoor time resulted in an odds ratio for obesity of 1.9 (95\% Cl: 0.9 - 4.0), which missed significance on a Chi²-test. For overweight no group difference could be observed (odds ratio: 1.2 (95 \% Cl: 0.7 - 2.0)). For substantiating these results the same calculations were carried out defining overweight and obesity according to the recommendations of the International Obesity Task Force. This evaluation yielded very similar results to those displayed in Fig. 2.

\section{Discussion}

\subsection{German children's time-location patterns}

In GerES IV time location-patterns of children were associated with age, as observed in various other studies (e .g. Brasche \& Bischof 2005; Echols et al. 1999). The increase of the time spent in other indoor environments with increasing age can plausibly be explained by increasing school time: The age gradient in time spent in other indoor environments is in good agreement with the increase in school time by grade stipulated by German school regulations (e. g. MSW 2010). Increasing school time is the most obvious reason for the decrease in outdoor time and time spent at home with increasing age. The fact that there are no gender differences in GerES IV is supported by findings of Brasche \& Bischof (2005) who observed almost identical mean times spent at home in German 7- to 16-year-old males and females.

Outdoor time decreases with increasing SES which may be explained by a possibly higher fraction of children walking to school in the lower SES group (Carlin et al. 1997). Consistently, a study by Ross (2000) found residents of poor neighborhoods being more likely to walk than those in less disadvantaged places. This effect can be assumed to apply for children, too. The SES is also associated with the time spent at home and in other indoor environments. However, no consistent SES gradient could be observed. It has been observed for the KiGGS participants that immigrant children more often fall into a low SES group than nonimmigrant children (Robert Koch Institute 2008). Thus, lower outdoor time of immigrant 
children cannot be explained by a higher SES. Different patterns in family life might be hypothesized as a possible reason. This assumption is supported by studies concluding immigrants to be more family-oriented (Foner 1997; Shields \& Behrman 2004).

Recently, scholarly debate has focused on the residential environment being associated with children's time-location pattern and their physical activity. It has been argued that the specific perception of the neighborhood may discourage (Timperio et al. 2004) or stimulate (Santos et al. 2009) children's outdoor activities. These findings are in line with the outdoor time being shorter in urban than in rural areas of Germany in GerES IV. As detached houses are likely to provide easy access to protected recreational spaces (e. g. private gardens and front yards), parental safety concerns may be another reason why outdoor time is associated with the building development (Valentine \& McKendrick 1997; Handy et al. 2008). A generalization of this hypothesis, however, is debatable as for example Burdette $\&$ Whitaker (2005) observed no association between the maternal perception of neighborhood safety and their children's outdoor play time.

Compared to the outdoor time of German 6- to 14-year-old children in GerES II conducted in 1990/92 (Heinemann et al. 1997), no substantial change in outdoor time of this age group can be concluded for Germany. In contrast to U.S. studies (Hofferth 2009), GerES data do not advocate a considerable shift in children's outdoor time in recent years. This discrepancy reflects the complex and multi-causal nature of children's time-location patterns that may vary between different countries. Concerning time-use-data (i. e. information on time spent daily for different everyday activities) on adults, an international survey has already been conducted at the European level. However, no consistent and complete time-location data can be derived from this Harmonized European Time Use Survey (HETUS) due to its study design (Eurostat 2009). Whereas during the KiGGS and GerES IV survey period, half-day school was the predominant school-type in Germany, the German Federal Government has been promoting all-day schooling in recent years (BMBF 2005; Fong 2007). This example demonstrates that important factors of children's time-location patterns are subject to change over time. Therefore, regular monitoring of time-location data on a populationrepresentative basis is necessary.

\subsection{Outdoor time, physical activity, and overweight}

KiGGS and GerES IV data are suitable for detecting correlations between outdoor time and physical activity. Consistently, Klesges et al. (1990) reported a correlation coefficient of 0.34 
between outdoor time and physical activity in pre-schoolers. Similar correlations have been found by Burdette et al. (2004). Correlations might be to some extent lower in GerES IV, as this sample includes children up to 14 years of age. The assessment of usual physical activity in study participants up to 10 years of age is different from that in older study participants: there is no self-assessment in the younger group and sport activity is not considered. Therefore, we cannot exclude that there may be some degree of misclassification in the data, which may in particular potentially underestimate the extent of physical activity in children below 10 .

The fact that Alhassan et al. (2007) found no increase in physical activity with outdoor time in an intervention study may be due to the limited size and specific characteristics of their sample of 32 Latino pre-schoolers.

In consistency with physical activity, also obesity is associated with outdoor time in German children. This result is in agreement with Cleland et al. (2008) who found time spent outdoors to be correlated with the prevalence of overweight in 10- to 12-year-old children in a longitudinal study. The quite weak associations between outdoor time and overweight with odds ratios less than 2 observed in our study may be partly due to secondary variables that might confound the correlation analysis. For example, our analysis did not take the nutritional behavior of the children into account.

Our results support the hypothesis of outdoor time being associated with physical activity and overweight. As the current degree of physical activity especially in German adolescents still needs improving (Lampert et al. 2007), public health strategies aiming at increasing physical activity should also take interventions aiming at reducing children's indoor activities into consideration, as e. g. suggested by Cleland et al. (2010).

An increase in outdoor time may under certain circumstances also be detrimental to children's health. In case of elevated concentrations of air contaminants in the neighborhood, children with high outdoor time are subject to higher environmental exposures (Wu et al. 2010). In this context higher outdoor time of low SES children might be of special concern, as the level of ambient air pollution may also be higher for children from low-income families (Gunier et al. 2003). Against this background, Villarreal-Calderón et al. (2002) identified a possible dilemma between physical fitness and adverse health effects of outdoor exposure. Therefore, strategies on increasing outdoor time of children should be accompanied by careful consideration of health-relevant environmental stressors like ambient air pollution and UV radiation. Milne et al. (2007) demonstrated that it is possible to 
reduce children's outdoor time for less UV radiation exposure without affecting their BMI. When weighing different opportunities of intervention, it has also to be considered that indoor air quality might even be more relevant for children's health (Dasgupta et al. 2006).

\subsection{Strengths and limitations of the study}

Strengths and limitations have to be particularly discussed concerning the study design and our approach of measuring the time-location data.

The survey yields representative reference data allowing our results to be generalized for the German children population. The large sample size is another important strength of GerES IV allowing precise estimates of average time-location parameters. The advantage of a large sample also applies for deriving reference distributions, as the sample size does influence goodness-of-fit outcomes. However, the quality of the distribution fits also depends on the accordance between data and model assumptions. In this regard, it has to be seen as a limitation that the Xprob algorithm does not consider mixed distributions. An additional essential strength of the study design is that it supports investigating associations between time-location data and health-relevant parameters. The crosssectional design, however, is an important limitation, as causality cannot be inferred. Concerning measuring time-location information, GerES IV relied on retrospective survey questions as did many other studies (e. g. Villarreal-Calderón et al. 2002; Burdette et al. 2004; Brasche \& Bischof 2005). KiGGS and GerES IV involved detailed medical examinations, extensive interviews on various topics, and investigations in the participant's homes. Therefore, retrospective survey measures appear particularly appropriate as they offer the important advantage of brevity. As all retrospective measures, parental reports may, however, not be free of inaccuracies. For example, recall or social desirability biases may have affected precision and validity of the data, which can be regarded as possible limitations in our study. Detailed time-activity diaries have been applied in various studies for deriving information on time-location patterns (Silvers et al. 1994; Klepeis et al. 2001; Wu et al. 2010). Although time-activity diaries are often considered to yield more reliable data, they are more expensive and time-consuming to conduct and to analyze (Schulz \& Grunow 2007). Moreover, supporting parents by specifically instructed interviewers in recalling and summarizing the overall time at home and outdoors can be assumed to compensate for possible limitations of retrospective interviews and to have substantially improved data quality. Referring to the last typical week also appears to be appropriate, as people tend to 
schedule activities on a weekly basis (Gershuny et al. 1986). Season and day-type are important influencing factors of time-location patterns (McCurdy \& Graham 2003). As these factors have been considered in the interview, a further improvement of the parental reports' validity can be expected.

Within recent years, applying GPS technology for recording time-location information gained momentum. This approach has been demonstrated to be suitable also for studies on children and promises substantial advantages concerning data quality (Elgethun et al. 2003). A study on 31 US children comparing GPS tracking information to parental time diary data

\footnotetext{
${ }^{2}$ For additional information on obtaining both public use files, see www.kiggs.de and www.uba.de/survey.
} suggests that parents may overestimate the time spent at home while underestimating the time spent in other locations (Elgethun et al. 2007). However, directly measuring timelocation patterns with GPS tracking participants or possibly burdensome multi-day timelocation diaries is generally of low feasibility in large-scale epidemiological studies. Despite potential limitations of our measurements, differences in time-location data by season and day-type are in good agreement with expectation and strengthen our confidence in the overall validity of our measurements.

\section{Conclusions and outlook}

The present study provides a current compilation of time-location data on German 3- to 14year-old children. Several associations between the time usually spent in different locations and socio-demographic and residential aspects could be identified. Moreover, GerES IV data were shown to be suitable for deriving probability distribution functions. These reference distributions offer broad applicability in probabilistic exposure modeling, e. g. concerning indoor air contaminants in German dwellings. Information collected in GerES IV also proved to be appropriate for elucidating associations between time-location patterns and health determinants in German children, when being linked to KiGGS data. Public use files of KiGGS and GerES IV data are available for further statistical evaluation ${ }^{2}$.

Based on the experiences in GerES IV, future large-scale population studies on environmental health should also include obtaining time-location data. The comparative application of other methods of data recording like GPS tracking is recommended for further eliminating uncertainties and biases due to possibly imperfect parental reports on the timelocation patterns of their children. As the time-location pattern is associated with various 
aspects on children's health, corresponding information should also be obtained in longitudinal studies for verifying anticipated causal relationships.

In particular, associations between SES, the residential environment, and time-location patterns have to be subject of further multivariate analyses. These investigations should take additional predictors as the parental occupational status, available living-space, family situation, and leisure time activities into account. This approach should give further insight into German children's time-location patterns and is likely to support public health strategies with respect to targeting risk communication on healthy behavior in German children.

\section{Acknowledgements}

We are highly indebted to the study participants and their parents and to the regional health and environmental offices supporting our work at the local level. Financial support of the GerES IV by the German Federal Ministry for the Environment, Nature Conservation and Nuclear Safety and the German Federal Ministry of Education and Research, and financial support of the KiGGS study by the German Federal Ministry of Health is gratefully acknowledged. We wish to thank our colleagues at the Federal Environment Agency, particularly Marike-Kolossa-Gehring, Christine Schulz, Kerstin Becker, Helga Pick-Fuß, and Catrin Zigelski, and our colleagues at the Robert Koch Institute for their help, support, and encouragement.

\section{Conflict of interest}

The authors declare no conflict of interest related to this work.

\section{References}

Alhassan, S., Sirard, J.R. \& Robinson, T.N., 2007. The effects of increasing outdoor play time on physical activity in Latino preschool children. International Journal of Pediatric Obesity, 2(3), pp.153-158.

Ali, F.N. et al., 2009. Vitamin D Deficiency in Children With Chronic Kidney Disease: Uncovering an Epidemic. Pediatrics, 123(3), pp.791-796.

Aschpurwis + Behrens GmbH, 2001. BIK-REGIONEN, Ballungsräume, Stadtregionen Mittel-/ Unterzentrengebiete, Methodenbeschreibung zur Aktualisierung 2000, Hamburg. Available at: http://www.bik-gmbh.de/texte/BIKRegionen2000.pdf.

Behrens, K., 2005. [City regions: From Boustedt to BIK]. In Regionale Standards. Mannheim: ZUMA, pp. 59-91.

BMBF, 2005. All-day schools. Time for more. Federal Ministry of Education and Research (Bundesministerium für Bildung und Forschung - BMBF). Available at: http://www.bmbf.de/en/1125.php [Accessed March 15, 2011].

Brasche, S. \& Bischof, W., 2005. Daily time spent indoors in German homes--baseline data for the assessment of indoor exposure of German occupants. International Journal of Hygiene and Environmental Health, 208(4), pp.247-253. 
Burdette, H.L. \& Whitaker, R.C., 2005. A National Study of Neighborhood Safety, Outdoor Play, Television Viewing, and Obesity in Preschool Children. Pediatrics, 116(3), pp.657-662.

Burdette, H.L., Whitaker, R.C. \& Daniels, S.R., 2004. Parental Report of Outdoor Playtime as a Measure of Physical Activity in Preschool-aged Children. Arch Pediatr Adolesc Med, 158(4), pp.353-357.

Carlin, J.B. et al., 1997. Walking to school and traffic exposure in Australian children. Australian and New Zealand Journal of Public Health, 21(3), pp.286-292.

Ciampi, A., Hogg, S.A. \& Kates, L., 1986. Regression analysis of censored survival data with the generalized F family--an alternative to the proportional hazards model. Statistics in Medicine, 5(1), pp.85-96.

Cleland, V. et al., 2008. A prospective examination of children's time spent outdoors, objectively measured physical activity and overweight. Int J Obes, 32(11), pp.1685-1693.

Cleland, V. et al., 2010. Predictors of time spent outdoors among children: 5-year longitudinal findings. Journal of Epidemiology and Community Health, 64(5), pp.400-406.

Cole, T.J. et al., 2000. Establishing a standard definition for child overweight and obesity worldwide: international survey. BMJ, 320(7244), p.1240.

Dasgupta, S. et al., 2006. Who suffers from indoor air pollution? Evidence from Bangladesh. Health Policy and Planning, 21(6), pp.444 -458.

Dölle, R, Schaffrath Rosario, A \& Stolzenberg, H, 2007. [The German Health Interview and Examination Survey for Children and Adolescents (KiGGS): data management]. Bundesgesundheitsblatt, Gesundheitsforschung, Gesundheitsschutz, 50(5-6), pp.567-572.

Dollman, J., Norton, K. \& Norton, L., 2005. Evidence for secular trends in children's physical activity behaviour. British Journal of Sports Medicine, 39(12), pp.892 -897.

Echols, S.L. et al., 1999. Temporal variability of microenvironmental time budgets in Maryland. Journal of Exposure Analysis and Environmental Epidemiology, 9(5), pp.502-512.

Elgethun, K. et al., 2003. Time-location analysis for exposure assessment studies of children using a novel global positioning system instrument. Environmental Health Perspectives, 111(1), pp.115-122.

Elgethun, K. et al., 2007. Comparison of global positioning system (GPS) tracking and parent-report diaries to characterize children's time-location patterns. Journal of Exposure Science \& Environmental Epidemiology, 17(2), pp.196-206.

Elizondo-Montemayor, L. et al., 2010. Serum 25-Hydroxyvitamin D Concentration, Life Factors and Obesity in Mexican Children. Obesity, 18(9), pp.1805-1811.

Eurostat, 2009. Harmonised European time use surveys - 2008 guidelines, Luxembourg: Methodologies and working papers. Available at: http://epp.eurostat.ec.europa.eu/cache/ITY_OFFPUB/KS-RA-08-014/EN/KS-RA-08-014-EN.PDF.

Foner, N., 1997. The Immigrant Family: Cultural Legacies and Cultural Changes. International Migration Review, 31(4), pp.961-974.

Fong, D., 2007. School in the Afternoon Is New to Germany, But Catching On. Deutsche Welle. Available at: http://www.dwworld.de/dw/article/0,,2380902,00.html [Accessed March 15, 2011].

Frumkin, H., 2005. Environmental health: from global to local, John Wiley and Sons.

Gershuny, J. et al., 1986. Time budgets: Preliminary analyses of a national survey. The Quarterly Journal of Social Affairs, 2(1), pp.13-39.

Gunier, R.B. et al., 2003. Traffic density in California: Socioeconomic and ethnic differences among potentially exposed children. J Expo Anal Environ Epidemiol, 13(3), pp.240-246.

Ham, S.A., Martin, S. \& Kohl, H.W., 2008. Changes in the percentage of students who walk or bike to school-United States, 1969 and 2001. Journal of Physical Activity \& Health, 5(2), pp.205-215. 
Handy, S., Cao, X. \& Mokhtarian, P., 2008. Neighbourhood Design and Children's outdoor play: Evidence from Northern California. Children, Youth and Environments, 18(2), pp.160-179.

Heinemann, L. et al., 1997. [German Environmental Survey 1990/92, Report Ilb: Questionnaire data on population exposure in the residential environment und on selected aspects of environmental protection in Germany], Berlin: ZEG Zentrum für Epidemiologie und Gesundheitsforschung.

Hensher, D.A. \& Button, K.J., 2000. Handbook of transport modelling, Emerald Group Publishing.

Hofferth, S.L., 2009. Changes in American children's time - 1997 to 2003. Electronic international journal of time use research, 6(1), pp.26-47.

Hubal, E.A.C. et al., 2000. Children's Exposure Assessment: A Review of Factors Influencing Children's Exposure, and the Data Available to Characterize and Assess That Exposure. Environmental Health Perspectives, 108(6), pp.475-486.

Kamtsiuris, P, Lange, M \& Schaffrath Rosario, A, 2007. [The German Health Interview and Examination Survey for Children and Adolescents (KiGGS): sample design, response and nonresponse analysis]. Bundesgesundheitsblatt, Gesundheitsforschung, Gesundheitsschutz, 50(5-6), pp.547-556.

Kleiser, C. et al., 2009. Potential determinants of obesity among children and adolescents in Germany: results from the cross-sectional KiGGS study. BMC Public Health, 9(1), p.46.

Klepeis, N.E. et al., 2001. The National Human Activity Pattern Survey (NHAPS): a resource for assessing exposure to environmental pollutants. Journal of Exposure Analysis and Environmental Epidemiology, 11(3), pp.231-252.

Klesges, R.C. et al., 1990. Effects of obesity, social interactions, and physical environment on physical activity in preschoolers. Health Psychology, 9(4), pp.435-449.

Kromeyer-Hauschild, K. et al., 2001. [Body-Mass-Index Percentiles for Children and Adolescents considering different German Samples]. Monatsschrift Kinderheilkunde, 149(8), pp.807-818.

Kurth, Bärbel-Maria, Kamtsiuris, Panagiotis, et al., 2008. The challenge of comprehensively mapping children's health in a nation-wide health survey: Design of the German KiGGS-Study. BMC Public Health, 8(1), p.196.

Kurth, B-M \& Schaffrath Rosario, A, 2010. [Overweight and obesity in children and adolescents in Germany]. Bundesgesundheitsblatt, Gesundheitsforschung, Gesundheitsschutz, 53(7), pp.643-652.

Lampert, T. et al., 2007. [Physical activity among children and adolescents in Germany. Results of the German Health Interview and Examination Survey for Children and Adolescents (KiGGS)]. Bundesgesundheitsblatt, Gesundheitsforschung, Gesundheitsschutz, 50(5-6), pp.634-642.

Landrigan, P.J. et al., 2004. Children's health and the environment: public health issues and challenges for risk assessment. Environmental Health Perspectives, 112(2), pp.257-265.

Lange, $\mathrm{M}$ et al., 2007. [Sociodemographic characteristics in the German Health Interview and Examination Survey for Children and Adolescents (KiGGS) - operationalisation and public health significance, taking as an example the assessment of general state of health]. Bundesgesundheitsblatt, Gesundheitsforschung, Gesundheitsschutz, 50(56), pp.578-589.

Leech, J.A. et al., 2002. It's about time: A comparison of Canadian and American time-activity patterns. J Expo Anal Environ Epidemiol, 12(6), pp.427-432.

McBrien, N.A. et al., 2008. Myopia: Recent Advances in Molecular Studies; Prevalence, Progression and Risk Factors; Emmetropization; Therapies; Optical Links; Peripheral Refraction; Sclera and Ocular Growth; Signalling Cascades; and Animal Models. Optometry and Vision Science: Official Publication of the American Academy of Optometry. Available at: http://www.ncbi.nlm.nih.gov/pubmed/19104470 [Accessed January 2, 2011].

McCurdy, T. \& Graham, S.E., 2003. Using human activity data in exposure models: Analysis of discriminating factors. J Expo Anal Environ Epidemiol, 13(4), pp.294-317.

Mekel, O. et al., 2007. [Evaluation of standard values and models for probabilistic exposure estimation], Dessau-Roßlau: Umweltbundesamt. Available at: http://www.umweltdaten.de/publikationen/fpdf-I/3357.pdf. 
Milne, E. et al., 2007. Time spent outdoors at midday and children's body mass index. American Journal of Public Health, 97(2), pp.306-310.

Mosbach-Schulz, O. et al., 2006. Unsupervised Fit of Distributions for Probabilistic Exposure Factors. Epidemiology, 17(6), p.S506-S507.

MSW, 2011. Verordnung zur Ausführung des § 93 Abs. 2 Schulgesetz (Schulgesetz NRW - SchulG), Available at: http://www.schulministerium.nrw.de/BP/Schulrecht/Verordnungen/93_2.pdf [Accessed January 30, 2011].

Peng, Y., Dear, K.B.G. \& Denham, J.W., 1998. A generalized F mixture model for cure rate estimation. Statistics in Medicine, 17, p.813--830.

Robert Koch Institute, 2008. [KiGGS: Children and adolescents with a migrational background in Germany], Robert Koch Institute. Available at: http://www.kiggs.de/experten/downloads/dokumente/KiGGS_migration[1].pdf.

Ross, C.E., 2000. Walking, exercising, and smoking: does neighborhood matter? Social Science \& Medicine (1982), 51(2), pp.265-274.

Sallis, J.F., Prochaska, J.J. \& Taylor, W.C., 2000. A review of correlates of physical activity of children and adolescents. Medicine and Science in Sports and Exercise, 32(5), pp.963-975.

Santos, M.P. et al., 2009. Perceptions of the built environment in relation to physical activity in Portuguese adolescents. Health \& Place, 15(2), pp.548-552.

SAS Institute Inc., 2010. SAS Software, Version 9.2 (Modules: BASE, STAT, IML), Cary, NC, USA.

Schenk, L, Ellert, U \& Neuhauser, H, 2007. [Children and adolescents in Germany with a migration background. Methodical aspects in the German Health Interview and Examination Survey for Children and Adolescents (KiGGS)]. Bundesgesundheitsblatt, Gesundheitsforschung, Gesundheitsschutz, 50(5-6), pp.590-599.

Schulz, C et al., 2007. Twenty years of the German Environmental Survey (GerES): human biomonitoring--temporal and spatial (West Germany/East Germany) differences in population exposure. International Journal of Hygiene and Environmental Health, 210(3-4), pp.271-297.

Schulz, Christine et al., 2008. [The German Environmental Survey for Children 2003-2006 (GerES IV): Sample and study design]. Umweltmedizin in Forschung und Praxis, 13(6), pp.379-390.

Schulz, F. \& Grunow, D., 2007. Comparing Time Diary Data and Stylized Time Use Estimates (Working Paper 2007-05), New Haven: Yale University. Available at: http://www.yale.edu/ciqle/CIQLEPAPERS/CIQLEWP2007-5.pdf.

Shields, M.K. \& Behrman, R.E., 2004. Children of Immigrant Families: Analysis and Recommendations. Children of Immigrant Families, 14(2), pp.4-15.

Silvers, A. et al., 1994. How Children Spend Their Time: A Sample Survey for Use in Exposure and Risk Assessments. Risk Analysis, 14(6), pp.931-944.

SPSS Inc., 2008. SPSS for Windows (17.0.0), Chicago. Available at: http://www.spss.com.

Sturm, R., 2005. Childhood Obesity - What We Can Learn From Existing Data on Societal Trends, Part 1. Preventing chronic disease [electronic resource], 2(1). Available at: http://www.cdc.gov/pcd/ issues/2005/jan/04_0038.htm.

Tamburlini, G., von Ehrenstein, O.S. \& Bertollini, R., 2002. Children's health and environment, Luxembourg: Office for Official publications of the European communities.

Timperio, Anna et al., 2004. Perceptions about the local neighborhood and walking and cycling among children. Preventive Medicine, 38(1), pp.39-47.

US EPA, 2000. A System for Fitting Distributions to Exposure Factor Data. In Options for Development of Parametric Probability Distributions for Exposure Factors (EPA/600/R-00/058). Washington, D.C.: National Center for Environmental Assessment. Available at: http://www.epa.gov/ncea/pdfs/paramprob4ef/chap2.pdf.

Valentine, G. \& McKendrick, J., 1997. Children's outdoor play: Exploring parental concerns about children's safety and the changing nature of childhood. Geoforum, 28(2), pp.219-235. 
Veitch, J. et al., 2006. Where do children usually play? A qualitative study of parents' perceptions of influences on children's active free-play. Health \& Place, 12(4), pp.383-393.

Villarreal-Calderón, A. et al., 2002. Assessment of physical education time and after-school outdoor time in elementary and middle school students in south Mexico City: the dilemma between physical fitness and the adverse health effects of outdoor pollutant exposure. Archives of Environmental Health, 57(5), pp.450-460.

Wu, X.M., Fan, Z.T. \& Ohman-Strickland, P., 2010. Time-location patterns of a population living in an air pollution hotspot. Journal of Environmental and Public Health, 2010. Available at: http://www.ncbi.nlm.nih.gov/pubmed/20445735 [Accessed February 2, 2011]. 
Tab. 1: Time German children (3-14 years) spend in different locations per day, stratified by age group and gender [hours:minutes/day]

\begin{tabular}{|c|c|c|c|c|c|c|c|c|c|c|c|c|}
\hline \multirow[b]{2}{*}{ At home } & & \multirow{2}{*}{$\frac{\mathbf{N}}{1670}$} & \multirow{2}{*}{$\frac{\text { Min }}{09: 26}$} & \multirow{2}{*}{$\frac{\text { P05 }}{13: 00}$} & \multirow{2}{*}{$\frac{\text { P25 }}{14: 34}$} & \multirow{2}{*}{$\frac{\text { P50 }}{15: 30}$} & \multirow{2}{*}{$\frac{\text { P75 }}{16: 30}$} & \multirow{2}{*}{$\frac{\text { P95 }}{17: 51}$} & \multirow{2}{*}{$\frac{\text { Max }}{21: 30}$} & \multirow{2}{*}{$\frac{\text { AM }}{15: 31}$} & \multicolumn{2}{|c|}{$95 \% \mathrm{Cl}$ AM } \\
\hline & & & & & & & & & & & $15: 24$ & - $15: 37$ \\
\hline \multicolumn{13}{|c|}{ Age group $* * *$} \\
\hline & $3-5$ years & 383 & $10: 11$ & $13: 43$ & $15: 21$ & $16: 17$ & $17: 21$ & $18: 34$ & $21: 30$ & $16: 19$ & $16: 07$ & - $16: 31$ \\
\hline & $6-8$ years & 419 & $10: 21$ & $13: 17$ & $14: 45$ & $15: 39$ & $16: 26$ & $17: 41$ & 19:04 & $15: 35$ & $15: 25$ & - $15: 45$ \\
\hline & $9-11$ years & 414 & $10: 39$ & $13: 13$ & $14: 21$ & $15: 15$ & $16: 13$ & $17: 13$ & 19:04 & $15: 14$ & $15: 04$ & - $\quad 15: 24$ \\
\hline & $12-14$ years & 454 & $09: 26$ & $12: 17$ & $14: 04$ & $15: 04$ & $16: 04$ & $17: 19$ & $18: 51$ & $15: 00$ & $14: 50$ & - $15: 10$ \\
\hline \multicolumn{13}{|l|}{ Gender } \\
\hline & Boys & 851 & $10: 11$ & $12: 43$ & $14: 31$ & $15: 39$ & $16: 32$ & $17: 49$ & 21:04 & $15: 32$ & $15: 23$ & - $15: 40$ \\
\hline & Girls & 819 & $09: 26$ & $13: 04$ & $14: 39$ & $15: 26$ & $16: 28$ & $17: 58$ & 21:30 & $15: 29$ & $15: 22$ & $\begin{array}{l}-\quad 15: 37 \\
\end{array}$ \\
\hline Other ind & renv. & 1670 & 00:00 & $02: 19$ & $03: 45$ & $04: 45$ & $05: 43$ & $07: 19$ & $10: 16$ & $04: 46$ & $04: 40$ & - $04: 52$ \\
\hline \multicolumn{13}{|c|}{ Age group $* * *$} \\
\hline & $3-5$ years & 383 & $00: 00$ & $01: 26$ & $02: 45$ & 03:39 & $04: 34$ & $06: 13$ & $08: 15$ & $03: 42$ & 03:31 & - 03:52 \\
\hline & $6-8$ years & 419 & 00:00 & $02: 30$ & $03: 36$ & $04: 26$ & $05: 21$ & $06: 34$ & $09: 21$ & $04: 28$ & $04: 20$ & - $04: 37$ \\
\hline & $9-11$ years & 414 & 01:11 & 03:17 & $04: 17$ & $05: 00$ & $05: 51$ & $07: 36$ & 10:04 & 05:08 & 04:59 & $-\quad 05: 18$ \\
\hline & $12-14$ years & 454 & $02: 26$ & 03:34 & $04: 43$ & $05: 30$ & $06: 19$ & 08:00 & $10: 16$ & 05:36 & $05: 27$ & - $05: 45$ \\
\hline \multicolumn{13}{|l|}{ Gender } \\
\hline & Boys & 851 & $00: 00$ & $02: 21$ & $03: 42$ & 04:39 & 05:39 & $07: 21$ & $10: 04$ & $04: 43$ & $04: 35$ & - $04: 50$ \\
\hline & Girls & 819 & 00:00 & $02: 15$ & 03:50 & 04:51 & 05:43 & $07: 17$ & $10: 16$ & $04: 50$ & 04:43 & $\begin{array}{l}-\quad 04: 56 \\
\end{array}$ \\
\hline Outdoors & & 1670 & $00: 46$ & $01: 56$ & $02: 56$ & 03:39 & $04: 26$ & $05: 47$ & 08:09 & 03:43 & $03: 38$ & $\begin{array}{l}-\quad 03: 49\end{array}$ \\
\hline \multicolumn{13}{|c|}{ Age group *** } \\
\hline & $3-5$ years & 383 & 01:09 & $02: 13$ & $03: 15$ & 03:51 & $04: 45$ & 06:04 & 08:09 & 03:59 & 03:51 & - $04: 08$ \\
\hline & $6-8$ years & 419 & 01:02 & $02: 17$ & $03: 13$ & 03:51 & $04: 30$ & $05: 47$ & $07: 34$ & 03:56 & 03:49 & - $\quad 04: 04$ \\
\hline & $9-11$ years & 414 & $01: 13$ & $01: 58$ & $02: 51$ & $03: 34$ & 04:19 & $05: 45$ & $06: 43$ & 03:37 & $03: 30$ & - $03: 45$ \\
\hline & $12-14$ years & 454 & $00: 46$ & 01:39 & $02: 30$ & $03: 21$ & $04: 11$ & $05: 30$ & 07:04 & $03: 23$ & 03:16 & - $03: 30$ \\
\hline \multicolumn{13}{|l|}{ Gender } \\
\hline & Boys & 851 & $00: 51$ & 02:00 & $02: 58$ & 03:43 & $04: 26$ & 05:41 & $07: 13$ & 03:46 & 03:39 & - $03: 52$ \\
\hline & Girls & 819 & $00: 46$ & 01:49 & $02: 54$ & 03:36 & $04: 26$ & 05:47 & 08:09 & 03:41 & 03:35 & - $\quad 03: 47$ \\
\hline
\end{tabular}


Tab. 2: Time German children (3-14 years) spend in different locations per day, stratified by socio-economic and immigration status [hours:minutes/day]

\begin{tabular}{|c|c|c|c|c|c|c|c|c|c|c|c|}
\hline & $\mathbf{N}$ & Min & P05 & P25 & P50 & P75 & P95 & Max & AM & \multicolumn{2}{|c|}{$95 \% \mathrm{Cl}$ AM } \\
\hline At home & 1670 & $09: 26$ & $13: 00$ & $14: 34$ & $15: 30$ & $16: 30$ & $17: 51$ & $21: 30$ & $15: 31$ & $15: 24$ & $15: 37$ \\
\hline \multicolumn{12}{|c|}{ Socio-economic status $* * *$} \\
\hline Low & 386 & $09: 26$ & $13: 00$ & $14: 24$ & $15: 26$ & $16: 26$ & $18: 00$ & $21: 30$ & $15: 28$ & $15: 17$ & $15: 40$ \\
\hline Medium & 769 & $10: 21$ & $12: 30$ & $14: 26$ & $15: 24$ & $16: 21$ & $17: 39$ & $19: 13$ & $15: 20$ & $15: 11$ & $15: 29$ \\
\hline High & 497 & $10: 39$ & $13: 30$ & $14: 51$ & $15: 43$ & $16: 41$ & $18: 13$ & $21: 04$ & $15: 48$ & $15: 39$ & $\begin{array}{l}-\quad 15: 57 \\
-15\end{array}$ \\
\hline \multicolumn{12}{|l|}{ Immigration status $* *$} \\
\hline Immigrants & 205 & $11: 34$ & 13:04 & $14: 43$ & $15: 56$ & $16: 39$ & 18:06 & $21: 30$ & $15: 48$ & $15: 32$ & $-16: 04$ \\
\hline No immigrants & 1462 & $09: 26$ & $12: 54$ & $14: 34$ & $15: 28$ & $16: 30$ & $17: 49$ & $21: 04$ & $15: 28$ & $15: 21$ & $15: 35$ \\
\hline Other indoor env. & 1670 & $00: 00$ & $2: 19$ & $03: 45$ & $04: 45$ & $05: 43$ & 07:19 & $10: 16$ & $04: 46$ & $04: 40$ & $-\quad 04: 52$ \\
\hline \multicolumn{12}{|c|}{ Socio-economic status $* * *$} \\
\hline Low & 386 & $00: 16$ & $2: 19$ & 03:34 & $04: 30$ & $05: 34$ & $07: 13$ & $10: 16$ & 04:36 & $04: 26$ & $-\quad 04: 46$ \\
\hline Medium & 769 & 00:00 & $2: 30$ & 03:56 & $04: 51$ & $05: 51$ & 07:39 & $09: 45$ & 04:55 & $04: 47$ & $-\quad 05: 03$ \\
\hline High & 497 & 00:00 & 2:00 & 03:45 & $04: 46$ & $05: 34$ & 07:11 & $10: 04$ & $04: 40$ & 04:31 & - $\quad 04: 49$ \\
\hline \multicolumn{12}{|l|}{ Immigration status } \\
\hline Immigrants & 205 & 00:09 & $2: 24$ & 03:39 & $04: 37$ & $05: 36$ & 07:17 & $09: 45$ & $04: 42$ & $04: 27$ & $\begin{array}{l}-\quad 04: 57 \\
\end{array}$ \\
\hline No immigrants & 1462 & $00: 00$ & $2: 19$ & 03:45 & $04: 47$ & 05:43 & 07:19 & $10: 16$ & $04: 47$ & $04: 40$ & $-\quad 04: 53$ \\
\hline Outdoors & 1670 & $00: 46$ & $1: 56$ & $02: 56$ & 03:39 & $04: 26$ & 05:47 & 08:09 & 03:43 & 03:38 & - $\quad 03: 49$ \\
\hline \multicolumn{12}{|l|}{ Socio-economic status $* *$} \\
\hline Low & 386 & $00: 46$ & $2: 00$ & 03:09 & 03:49 & $04: 46$ & 06:04 & $07: 17$ & 03:56 & $03: 47$ & - $\quad 04: 05$ \\
\hline Medium & 769 & $00: 51$ & $1: 56$ & 02:56 & 03:41 & $04: 30$ & 05:51 & 08:09 & $03: 45$ & 03:38 & $\begin{array}{l}-\quad 03: 51 \\
\end{array}$ \\
\hline High & 497 & 01:17 & $1: 51$ & $02: 49$ & 03:30 & 04:11 & $05: 26$ & 08:00 & 03:32 & $03: 25$ & $-\quad 03: 39$ \\
\hline \multicolumn{12}{|l|}{ Immigration status $* * *$} \\
\hline Immigrants & 205 & 01:02 & $1: 51$ & $02: 39$ & 03:21 & $04: 21$ & $05: 34$ & $06: 15$ & 03:30 & 03:19 & - $\quad 03: 41$ \\
\hline No immigrants & 1462 & $00: 46$ & $1: 58$ & $02: 58$ & 03:41 & $04: 26$ & $05: 47$ & 08:09 & $03: 45$ & $03: 40$ & $-\quad 03: 50$ \\
\hline
\end{tabular}


Tab. 3: Time German children (3-14 years) spend in different locations per day, stratified by parameters of the residential environment [hours:minutes/day]

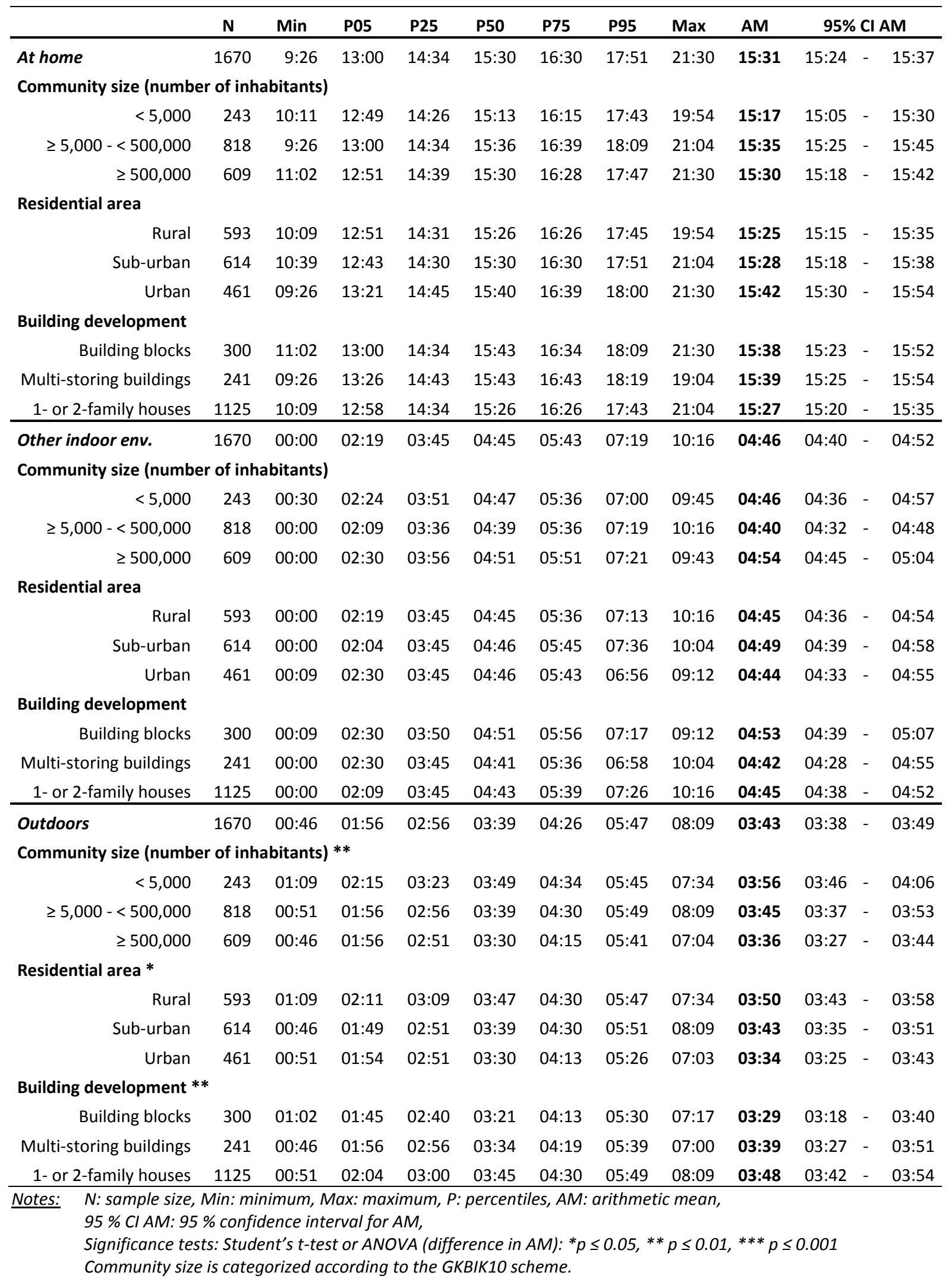


Tab. 4: Fitted statistical distributions of the time [minutes/day] German children (3-14 years) spend in different locations per day

\begin{tabular}{lllll}
\hline Location & Fit to GF distribution & $K S_{\text {emp }}$ & Best fit to sub-model & $K S_{G F}$ \\
\hline At home & $\mathrm{m}_{1}=1.129, \mathrm{~m}_{2}=2.438$ & 0.0194 & Log-logistic & 0.0191 \\
& $\lambda=0.001, \mathrm{p}=13.74$ & & $\alpha=18.08, \beta=930.0$ & \\
\hline In other indoor & $\mathrm{m}_{1}=0.461, \mathrm{~m}_{2}=1.309$ & 0.0171 & Weibull & 0.0266 \\
environments & $\lambda=0.003, \mathrm{p}=7.210$ & & $\alpha=3.410, \beta=318.9$ & \\
& $\mathrm{PMZ}=0.413 \%$ & & $\mathrm{PMZ}=0.413 \%$ & 0.0181 \\
\hline Outdoors & $\mathrm{m}_{1}=2.364, \mathrm{~m}_{2}=23.42$ & 0.0230 & Gamma & \\
& $\lambda=0.004, \mathrm{p}=2.291$ & & $\alpha=10.01, \beta=22.32$ & \\
\hline
\end{tabular}

Notes: GF distribution $=$ Generalized $F$ distribution, whereas $m_{1}$ and $m_{2}$ are the shape parameters and $\lambda$ and $p$ are the location and scale parameters according to the parameterization in Mekel et al. (2007); two-parametric distributions are parameterized according to the @Risk software(Palisade Corp. 2010), whereas $\alpha$ and $\beta$ are the shape and scale parameters of the distribution; PMZ = Point mass at zero (fraction of "zero minutes" observations); $K S=K o l m o g o r o v-S m i r n o v$ distance to empirical data $\left(K S_{\text {emp }}\right)$ or underlying GF model $\left(K S_{G F}\right)$ 
Tab. 5: Differences in mean outdoor time [hours:minutes/day] by reported level of physical activity in German children (3-14 years)

\begin{tabular}{rcc}
\hline $\begin{array}{c}\text { Physical activity } \\
(p<0.001)\end{array}$ & AM & O5\% Cl AM \\
\hline Low & $\mathbf{0 3 : 3 2}$ & $03: 24-03: 40$ \\
Medium & $\mathbf{0 3 : 4 3}$ & $03: 36-03: 49$ \\
High & $\mathbf{0 3 : 5 3}$ & $03: 45-04: 01$ \\
\hline
\end{tabular}

Notes: AM: arithmetic mean, $95 \% \mathrm{Cl}$ AM: $95 \%$ confidence interval for $A M$, Significance tests: ANOVA (difference in AM, including age as covariate) 


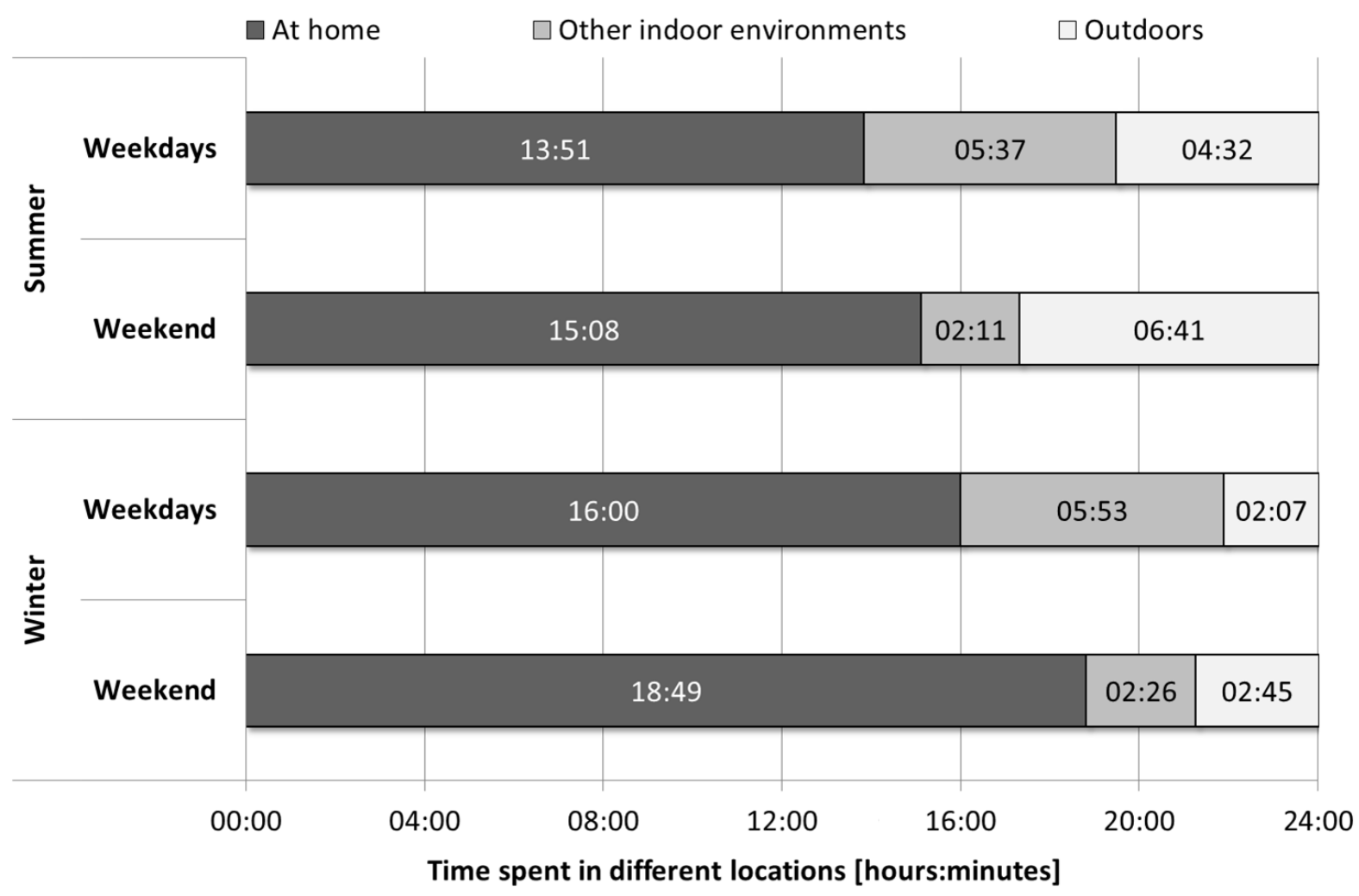

Fig. 1: Time German 3- to 14-year-old children spend per day in different locations, stratified by season and day type 


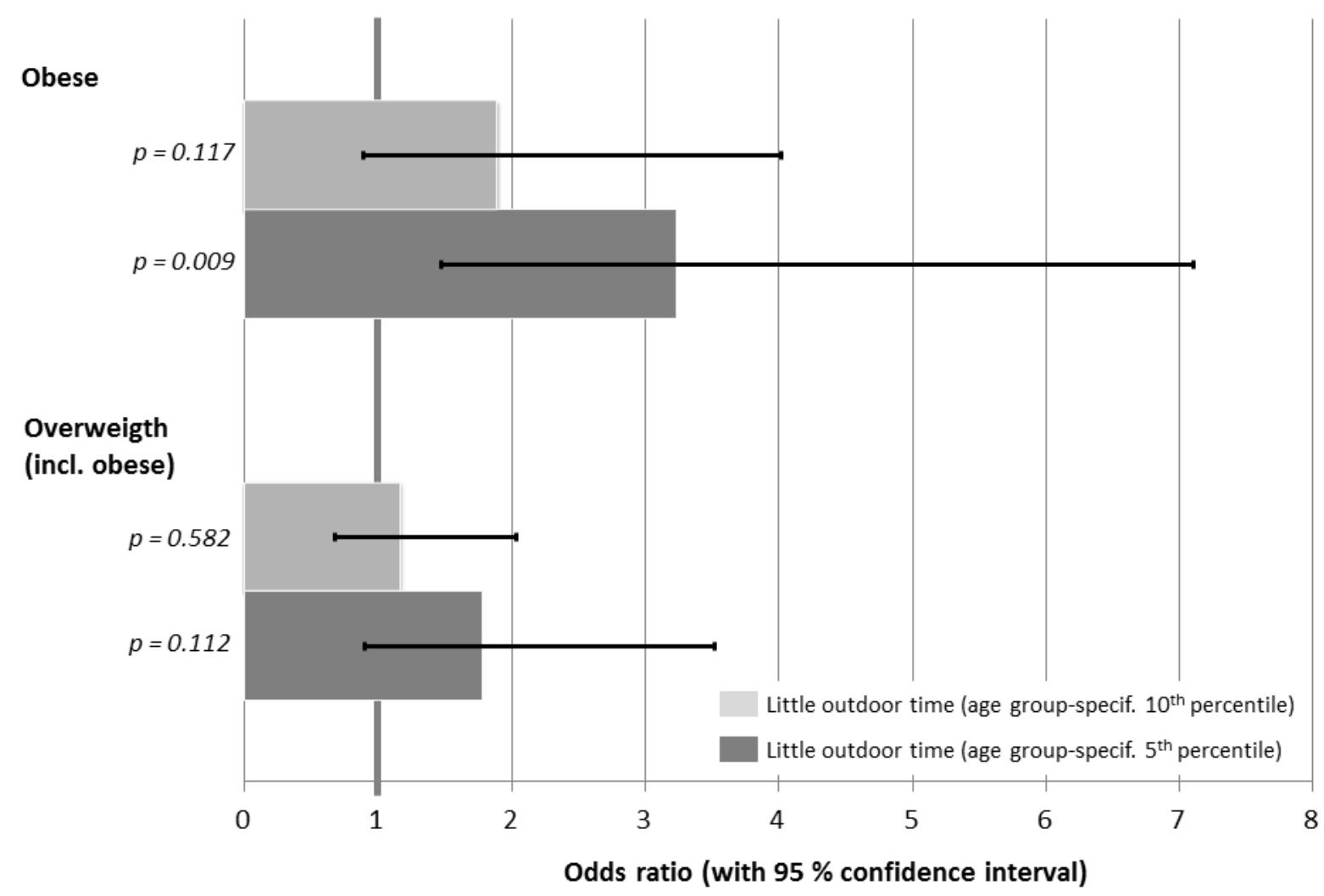

Fig. 2: Associations of little outdoor time (lower than age group-specific $5^{\text {th }} / 10^{\text {th }}$ percentiles) and being overweight or obese (according to definitions by Kromeyer-Hauschild): odds ratios with $95 \%$ confidence intervals and p-values of Chi ${ }^{2}$ test of independence 